\title{
Abastados terratenentes, caudilhos poderosos ou empresários arcaicos: os súditos do Império brasileiro no Uruguai e a historiografia
}

Wealthy landowners, powerful caudillos or archaic businessmen: the subjects of the Brazilian Empire in Uruguay and the historigraphy

Ricos terratenientes, caudillos poderosos o empresarios arcaicos: los súbditos del Imperio brasileño en Uruguay y la historigrafía

Carla Menegat

\section{Resumo}

Ao longo do século XIX, em diferentes momentos, produtores brasileiros instalados no país vizinho se dirigiram a diferentes autoridades do Império solicitando intervenções em favor dos seus direitos constantemente violados por autoridades uruguaias. Os distúrbios que os assolavam provocavam imensa repercussão política e econômica, podendo gerar considerável crise. Formavam, junto com os charqueadores e comerciantes, o topo da hierarquia social no Rio Grande do Sul. A identificação dos estancieiros como abastados terratenentes, caudilhos poderosos ou empresários arcaicos foi uma constante na historiografia, apenas recentemente abandonada. Procurando entender a trajetória que conduziu pesquisadores a sugerir novas interpretações sobre o tema, propõe-se neste estudo uma revisão dessa historiografia.

Palavras-chave: Estado nacional. Estancieiros. Fronteira.

Doutora em História pela Universidade Federal do Rio Grande do Sul. Docente do Instituto Federal Sul-Rio-Grandense. E-mail: carlamenegat@hotmail.com

Recebido em: 10/12/2017 - Aprovado em: 20/02/2018 http://dx.doi.org/10.5335/hdtv.18n.2.8070 
No ano de 1845 , mais de cem proprietários brasileiros estabelecidos no Estado Oriental assinaram carta expedida pela Câmara de Alegrete ao Conde de Caxias, Presidente da Província do Rio Grande do Sul. O notável conteúdo da missiva informava o leitor do relato detalhado da ocupação dos campos que iam daquela cidade até Salto, no Uruguai, conduzida primeiramente pela Coroa Portuguesa e depois pelo Império do Brasil. Ao longo do século XIX, em diferentes momentos, produtores brasileiros instalados no país vizinho se dirigiram a diferentes autoridades do Império solicitando intervenções a seu favor, alegando que seus direitos eram constantemente violados por autoridades uruguaias.

A percepção de que a garantia da fidelidade à nação e da legitimidade da soberania não se deu de imediato com a instalação do Estado Nacional no Brasil, mas se tratou de um processo, que se estendeu ao longo do século XIX, é tema clássico da historiografia brasileira. Durante muito tempo, os estudos foram polarizados por análises do tipo centralização $x$ descentralização ou estado $x$ sociedade, tornando-se um tanto unilaterais, além de muitas teses serem de difícil comprovação empírica, como a do patrimonialismo de Raymundo Faoro (1958), por exemplo.

Novos estudos revigoraram o debate sobre a construção do Estado Nacional se opondo às percepções de que a centralização do Estado durante o Império foi resultado do simples esmagamento das elites provinciais, sem considerar os seus interesses regionais e como essas elites agiam e interagiam com outras elites, contribuindo, as- sim, com a consolidação do Estado imperial (CARVALHO, 2003; MATTOS, 1990). A tese de José Murilo de Carvalho (2003) apontou uma série de perspectivas que, mesmo em alguns pontos superadas pelas pesquisas posteriores, são questões basilares ao debate. Esclarecendo noções importantes de hierarquia dentro da burocracia imperial, ou o papel do ensino superior como capital social e caminho de inserção na política monárquica, a obra é um divisor de águas na forma de construir a percepção do Estado Nacional em formação no século XIX.

$O$ redimensionamento do papel das elites provinciais na historiografia também tem aberto o campo de investigações ao discutir as relações destas com a corte. Rompendo com as percepções de que a implementação do Estado Nacional foi fruto da ação exclusiva dos agentes do centro do Império, estes estudos têm demonstrado que os interesses da corte não estavam descolados dos interesses das elites provinciais e locais, com seus políticos mantendo fortes vínculos com os proprietários de terra e negociantes de várias províncias.

Analisando o conselho de Estado, Maria Fernanda Vieira Martins identifica a existência de uma elite interprovincial que vinculava ricas famílias da Bahia, de São Paulo, de Minas Gerais, de Pernambuco e do Rio de Janeiro num jogo de alianças parentais e comprometimentos clientelares que transpassavam as simples rivalidades partidárias (MARTINS, 2005). Sua grande contribuição está, justamente, em explicitar o papel que as famílias tinham dentro desse conjunto, em parte, algo realizado por Richard Graham, apesar de este considerar os pro- 
prietários de terra como um grupo homogêneo guiado por relações clientelares (GRAHAM, 1997).

Por sua vez, Miriam Dolhnikoff, defendendo a percepção de que havia uma autonomia política com feições federativas, argumenta que a consolidação da monarquia não abriu mão do poder e da autonomia das elites provinciais, mas, pelo contrário, foi na negociação da elite imperial com as elites provinciais que a monarquia pôde firmar-se como modelo de governo da nação independente (DOLHNIKOFF, 2005). Martins (2005) não identifica o Rio Grande do Sul como parte desta rede política, e Dolhnikoff (2005) analisa-o exatamente por sua condição peculiar, enquanto estado fronteiriço, dentro da perspectiva de que sua atuação na política imperial reforça os traços de autonomia.

Traço marcante que se repete em outras pesquisas produzidas no centro do país (CARDOSO, 1977), a percepção de que há uma condição peculiar, geralmente identificada com a fronteira e seus desdobramentos, como os conflitos platinos e a infiltração de ideais republicanos, é pouco explicada. Teses como a de Fernando Uricoechea (1978), que apontam para a parca presença do Estado na província e tentam a partir disso afirmar um excesso de autonomia na ação dos homens de fronteira - no caso de Uricoechea, especificamente dos oficiais da Guarda Nacional -, acabam por construir modelos explicativos que reproduzem o discurso encontrado nos documentos oficiais produzidos na corte. Além disso, padecem do fato de, ao produzirem explicações generalistas, se deterem pouco sobre as ditas "peculiaridades" do contexto local.
Pesquisas acadêmicas que tratem especificamente da relação entre os estancieiros brasileiros estabelecidos no Estado Oriental e do poder central do Império são praticamente inexistentes. Nesse sentido, torna-se necessário destacar como os estancieiros, em geral e particularmente, vêm sendo tratados pela historiografia brasileira, sobretudo a local. Diversos estudos de história política foram produzidos nas décadas de 1970 e 1980, tratando do Rio Grande do Sul durante o Império (KLIEMANN, 1986; TRINDADE; NOLL, 1991; FONSECA, 1983; PICCOLO, 1974). Bastante representativo dessa produção, o trabalho de Helga Piccolo (1974) foi profundamente influenciado pela visão de Sérgio Buarque de Holanda (HOLANDA, 1985) e considerou os anseios de autonomia e o uso da violência como expressão de forças localistas arcaicas, apegadas aos privilégios coloniais que se opunham a construção da unidade nacional, modernizadora. Opondo a paz no Império às turbulências na Bacia do Prata, Piccolo caracteriza os estancieiros como caudilhos imersos no contexto de guerras e se alinha às interpretações que veem as ações deles como a manifestação de

[...] bolsões de poder privado, centrados em torno de oligarquias rurais que viviam praticamente independentes do poder central, de maneira alegal, e que solucionavam seus problemas sem interferir com ele e também sem sofrerem interferência (PICCOLO, 1998, p. 102).

A identificação dos estancieiros como abastados terratenentes, caudilhos poderosos ou empresários arcaicos foi uma constante na historiografia sobre a elite agrária da sociedade sulina do oitocentos. Esse é um 
daqueles temas em que um largo consenso está combinado com pouca análise empírica (FARINATTI, 2007, p. 20). Isso ocorre por que a maioria dos trabalhos acaba por não privilegiar um olhar que não se centre unicamente nos discursos parlamentares e na imprensa política, fontes com produção bastante específica, que não podem ser tomadas como representativas do conjunto do topo da hierarquia social. Alguns recentes trabalhos têm buscado romper com essa lógica, tentando entender como se constituíram as relações sociais dentro da elite política provincial (VARGAS, 2007), ou como se organizava a carreira militar naquele contexto de crescente profissionalização do exército (RIBEIRO, 2009).

Aliás, a própria compreensão da importância das guerras constantes na conformação daquela sociedade foi pouco entendida pela historiografia. Vista ora como a ineficiência do Estado em conseguir impor a soberania nacional, ora como fruto do expansionismo imperial, quando analisada sob a perspectiva da ação do poder central e a partir da ação dos agentes locais, sempre como a incapacidade de se adequarem às práticas políticas institucionalizadas, acabava por reforçar a percepção de que os estancieiros rio-grandenses eram em suma perfeitos caudilhos. Além de tudo, eram caudilhos conservadores que, ao utilizarem a força para resolver seus conflitos, impediam a instauração do moderno Estado de direito. O que muitas vezes foi desconsiderado por esta historiografia foi o fato marcante de que a presença mais clara do Estado na região sempre se deu por meio da guerra e de que residia nela um dos acessos privilegiados daqueles estancieiros ao poder central, num contexto em que carreira militar e carreira política estavam profundamente associadas (SOUZA, 2008, p. 463).

O impacto da dissidência farroupilha também é mal dimensionado. Se, numa análise da literatura, são possíveis perceber a dificuldade de criação de um panteão de heróis para a província (LAZZARI, 2004) e as dificuldades na relação com o centro por conta do peso da suspeita de dissidência (GOMES, 2009), não existem estudos que ponderem a dimensão que tal situação criou para o desenvolvimento da política no sistema monárquico. A tese de total exclusão da província é uma forma de evitar um debate mais profundo sobre como se constituíam os contatos e o encaminhamento de demandas, além de ignorar uma análise sobre as formas como as elites locais se articulavam com o centro do Império, mesmo em situações peculiares. Simplesmente apontar para o fato de que pesavam sobre os rio-grandenses a desconfiança do separatismo não explica como essas elites participavam da política. Se não havia rio-grandenses, alguém devia acorrer por eles.

Algumas pesquisas têm dado pistas desse processo. Adriana Barreto de Souza, em seu livro sobre Duque de Caxias, mostra que, logo após a pacificação da província, vários integrantes da comitiva enviada com Luís Alves de Lima e Silva foram candidatos pela província às eleições, sendo eleitos (SOUZA, 2008, p. 540). Além disso, a necessidade de relações sólidas pode ser demonstrada pelos vestígios de negociações quando do recrutamento para as campanhas de 1851 no Uruguai e de 1852 contra Rosas (MENEGAT, 2009, p. 168). 
A identificação dos estancieiros com ideais apreendidos no contato com o mundo platino é apontada recorrentemente como parte da tensão entre autonomia provincial e centralização nacional (GUAZZELLI, 1995). A perspectiva federativa, fruto do constante contato com os territórios vizinhos, norteou a interpretação sobre o uso da violência e sobre uma suposta dificuldade de garantir a implementação das instâncias institucionais como canal político de reivindicação. Mesmo a pesquisa de Dolhnikoff (2005) considera essa a especificidade da província, e, segundo sua interpretação, há um descolamento entre o poder local e o provincial. Nesse sentido, também se inserem trabalhos que retomam o tema clássico da diplomacia e da guerra entre os dois países (RECKZIEGEL, 1999; ZABIELA, 2002). Porém, sob essa perspectiva, o debate do pertencimento é deslocado para o campo do direito, excluindo a possibilidade de debate sobre as implicações das relações sociais imersas nesse contexto.

Precursoras nesse sentido, análises que percebem as relações entre o mundo platino e a identidade política rio-grandense (FIGUEIREDO, 2000; GUAZZELLI, 1998) contribuíram para o desenvolvimento de algumas novas premissas. Mas particularmente a noção de fronteira manejada (THOMPSON FLORES; FARINATTI, 2009), que pressupõe o uso intencional da fronteira como recurso, tem propiciado significativa alteração nos estudos de história social. Ao identificar a fronteira como recurso manejado pelos indivíduos, é possível observá-los ocupando outra posição em suas redes sociais, aquela em que sua condição nacional não está pressuposta, bem como sua lealda- de ou seu pertencimento. Mais do que um espaço distante do centro, a fronteira pode ser vista como um espaço de opção, onde projetos alternativos podem se tornar uma escolha; ou mesmo, onde a possibilidade de se tornar uma escolha é, em si mesma, um recurso.

Para além disso, recentemente, foi produzido um conjunto de estudos de história econômica e social que tem oferecido um revigoramento da história das elites a partir do seu tratamento coletivo, ora enfatizando as estratégias familiares, ora combinando-as com a análise das trajetórias individuais e, de certa forma, superando as caracterizações tradicionais da historiografia. Muitos desses estudos têm como premissa o fato de que as relações sociais e políticas mantidas pelos agentes históricos envolvidos também devem ser levadas em conta, quando se estuda a economia nas sociedades pré-industriais.

Neste ponto, cabe um destaque. $\mathrm{O}$ trabalho de Luís Augusto Eibling Farinatti, Confins Meridionais, trata da elite agrária de Alegrete no período de 1825-1865 (FARINATTI, 2007). Alguns dos questionamentos expressos à historiografia, inclusive a expressão que dá título a esse texto, foram retirados do estudo de Farinatti. Ao investigar as grandes fortunas daquela área de fronteira, Farinatti encontrou famílias, não apenas indivíduos, e uma distribuição de recursos e propriedades de ambos os lados da fronteira, funcionando como empresa comum. $\mathrm{E}$, no concurso das relações interpessoais dos indivíduos dessas famílias, também encontrou formas de organização e inserção na política. Especialmente, o autor aponta para a importância das relações com mili- 
tares, estabelecidas especialmente a partir do matrimônio, que garantiam uma posição privilegiada no contexto da fronteira. $\mathrm{O}$ caso dos Ribeiro de Almeida, família de Bento Manuel, controverso comandante que traiu os farroupilhas e passou ao lado dos liberais, é particularmente exemplar.

Personagens sempre protagonistas na vida da província no século XIX, os comandantes de fronteira nunca foram analisados muito detidamente. Surgem, na historiografia em geral, para corroborar afirmações a partir de suas comunicações oficiais com o Império ou com o governo provincial. Alguns desses indivíduos acabaram por participar de quase todos os conflitos ocorridos na região, e mesmo o número de citações nos dá a dimensão de sua presença. Porém, análises que esclareçam quem eram esses cidadãos do Império, como se inseriram no complexo quadro político e burocrático imperial e adquiriram notoriedade, com raras exceções, ainda não foram realizadas.

Como bem perceberam os historiadores que têm se dedicado ao estudo da história das regiões platinas, a província estava fortemente integrada ao vasto espaço fronteiriço conformado pelo território da atual República do Uruguai e das províncias argentinas de Buenos Aires, Santa Fé, Entre Rios e Corrientes (OSÓRIO, 1990). Com essas regiões, compartilhava: uma economia em que a pecuária ocupava lugar de destaque; a disseminação de uma combinação de relações de trabalho livres, escravas e familiares; o contexto de guerras recorrentes no século XIX; o crescimento da atividade charqueadora (e a competitividade acarretada por ele); entre outras características.
Uma série de trabalhos, orientados para as discussões sobre a fronteira e suas possibilidades de interação ou uso estratégico, surgiu recentemente propondo outras discussões a partir de novas metodologias de análise e preocupada com problemáticas diferenciadas, como a estrutura social do mundo agrário, o acesso à terra e o contrabando (GARCIA, 2005; THOMPSON FLORES, 2007), superando em parte a percepção desse descolamento entre poder local e poder central. Entre eles, o importante estudo de Suzana Bleil de Souza e Fabrício Prado se deteve mais sobre os estancieiros brasileiros no Uruguai, analisando "a evolução política da tensão entre os proprietários brasileiros e grupos de elite orientais durante o século XIX" (SOUZA; PRADO, 2004). Porém, o foco dos autores está intimamente ligado ao Estado uruguaio e sua percepção sobre estes estancieiros e não sobre as interações destes com o Império brasileiro, perspectiva semelhante a que os próprios historiadores uruguaios constroem sobre o tema.

O segundo destaque é a dissertação de mestrado de Mariana Flores da Cunha Thompson Flores (2007) sobre contrabando na fronteira meridional na segunda metade do século XIX. Ao debater a fronteira, a autora traz importante destaque sobre o já citado manejo da fronteira. Mas, para além disso, ao debater as percepções de legalidade, legitimidade e comércio, Thompson Flores contribui para a discussão da presença do Estado, de quem realmente o representa e de quanto ele é externo aquela realidade, além de suscitar importantes questionamentos na percepção da relação entre corte, província e poder local. 
Por fim, destaca-se a pesquisa de Graciela Bonassa Garcia (2005), que trata do acesso à terra na mesma fronteira de Alegrete. Ao pensar uma sociedade em que as desigualdades exigiam mediações nas relações sociais para garantir o acesso à terra, a autora descortina boa parte das formas como esse acesso se dava e, especialmente, o quanto os recursos sociais impactavam sobre as decisões oficiais.

A discussão sobre soberania e importância da tradição legal no Rio da Prata, realizada por autores platinos, oferece importante contribuição para pensar as relações e influências entre os territórios. Autores como José Carlos Chiaramonte, Ana Frega e Oswaldo Barreneche (CHIARAMONTE, 1997; FREGA, 2007; BARRENECHE, 2006) produziram trabalhos diretamente relacionados às questões das disputas de soberanias em competição, adaptações e experimentações legais que se desenrolaram no Rio da Prata no século XIX.

Especialmente o trabalho de Chiaramonte, cunhando o conceito de "região-província", explica como a profunda importância da cultura legal no Império espanhol influenciou as atitudes e práticas políticas, levando o regional e a esfera da comunidade para o primeiro plano na vida social dos agentes históricos no mundo platino pós-colonial (CHIARAMONTE, 1991). O autor ainda demonstra como redes comerciais que atravessam territórios fragmentados que antes compunham um todo dão sentido para pertencimentos e lealdades e dominam a organização econômica e política do Rio da Prata.
Mas é necessário fazer uma ressalva: a necessidade de identificar o Rio Grande do Sul no contexto platino não é o mesmo que dizer que em tudo este se assemelha aos vizinhos. Discurso corrente no século XIX, aliado à suspeita de separatismo, que despertou profundos debates na historiografia local durante todo o século XX, traz um pressuposto particular: os estancieiros eram caudilhos. Supondo mais uma vez que esses indivíduos estavam fora do jogo político imperial, ou por opção ou por condição, eis um debate inacabado.

\section{Considerações finais}

É no bojo desses trabalhos que se insere a perspectiva de pesquisa que proponho. Entender as relações dos pecuaristas brasileiros estabelecidos no Estado Oriental com o poder central e a forma como estas relações repercutiam na sua articulação na elite provincial exige uma análise que supere as tradicionais perspectivas da história militar, administrativa e diplomática. A escolha por esses estancieiros se deu pela combinação de dois fatores. O primeiro é a recorrente citação dos problemas que estes tinham no Estado Oriental como uma das causas dos conflitos platinos em que o Império esteve envolvido, seja a campanha contra Rosas e Oribe, seja a Guerra do Paraguai, ou, mesmo, o peso que tiveram sobre os descontentamentos que levaram à deflagração da Revolução Farroupilha.

A segunda é a total inexistência de estudos que caracterizem a formação social deste grupo, as suas relações políticas com outros setores da sociedade e as diferentes 
esferas de ocupação em que os seus membros estavam inseridos e que auxiliavam na manutenção da sua própria posição na hierarquia social. Compreender os processos que os colocavam no centro da política provincial e avaliar quais redes de sociabilidade e parentesco garantiam sua participação na articulação do sistema monárquico permitem que se constitua uma nova percepção sobre as elites na extemadura do Brasil.

\section{Abstract}

Throughout the nineteenth century, at different times, Brazilian producers installed in the neighboring country addressed the different authorities of the Empire requesting interventions in favor of their rights constantly violated by Uruguayan authorities. The disturbances that devastated them caused immense political and economic repercussions, and could generate considerable crisis. Together with the charqueadores and merchants, they formed the top of the social hierarchy in Rio Grande do Sul. Identification of the ranchers as wealthy landowners, powerful caudillos or archaic businessmen was a constant in historiography only recently abandoned. Trying to understand the trajectory that led researchers to propose new interpretations on the subject, we propose here a revision of this historiography.

Keywords: Border. National state. Ranchers.

\section{Resumen}

A lo largo del siglo XIX, en diferentes momentos, productores brasileños instalados en el país vecino se dirigieron a las diferentes autoridades del Imperio solicitando intervenciones en favor de sus derechos constantemente violados por autoridades uruguayas. Los disturbios que los asolaban provocaban una inmensa repercusión política y económica, pudiendo generar considerable crisis. La identificación de los estancieros como ricos terratenientes, caudillos poderosos o empresarios arcaicos fue una constante en la historiografía apenas recientemente abandonada. Buscando entender la trayectoria que condujo a investigadores a proponer nuevas interpretaciones sobre el tema, se propone aquí una revisión de esta historiografía.

Palabras clave: Estado nacional. Frontera. Ganaderos.

\section{Referências}

BARRENECHE, Osvaldo. Crime and the Administration of Justice in Buenos Aires, 1785-1853. Lincoln: University of Nebraska Press, 2006.

CARVALHO, José Murilo de. A Construção da Ordem: a elite política imperial e Teatro de Sombras: a política Imperial. Rio de Janeiro: Civilização Brasileira, 2003.

CHIARAMONTE, José Carlos. Ciudades, provincias, Estados: orígenes de la Nación Argentina (1800-1846). Buenos Aires: Ariel, 1997.

. Mercaderes del Litoral: economia y sociedad en la provincia de Corrientes, primera mitad del siglo XIX. Buenos Aires: Fondo de Cultura Económica, 1991. 
DOLHNIKOFF. Miriam. O Pacto Imperial. Origens do federalismo no Brasil. São Paulo: Globo, 2005.

FAORO, Raymundo. Os Donos do Poder: formação do patronato político brasileiro. Porto Alegre: Globo, 1958.

FARINATTI, Luis Augusto. Confins Meridionais: famílias de elite e sociedade agrária na fronteira sul do Brasil (1825-1865). 2007. Tese (Doutorado em História) - IFCS/UFRJ, Rio de Janeiro, 2007.

FIGUEIREDO, Joana Bosak. O Rio Grande de São Pedro entre o Império do Brasil e o Prata: a identidade regional e o Estado nacional (18511865). 2000. Dissertação (Mestrado em História) - UFRGS/PPGH, Porto Alegre, 2000.

FONSECA, Pedro Dutra. Economia e conflitos políticos na República Velha. Porto Alegre: Mercado Aberto, 1983.

FREGA, Ana. Pueblos y soberanía en la revolución artiguista. La región de Santo Domingo Soriano desde fines de la colonia a la ocupación portuguesa. Montevideo: Ediciones de la Banda Oriental, 2007.

GARCIA, Graciela B. O Domínio da Terra: conflitos e estrutura agrária na Campanha Rio-grandense Oitocentista. 2005. Dissertação (Mestrado em História) - PPGH/UFRGS, Porto Alegre, 2005.

GOMES, Carla Renata Antunes de Souza. De Rio-Grandense a Gaúcho: o triunfo do avesso. Um processo de representação regional $n$ literatura do século XIX (1847-1877). Porto Alegre: Editoras Associadas, 2009.

GRAHAM, Richard. Clientelismo e Política no Brasil do Século XIX. Rio de Janeiro: UFRJ, 1997. . O Horizonte da Província: a República Rio-grandense e os caudilhos do Rio da Prata (1835-1845). 1998. Tese (Doutorado em História) - PPGH/UFRJ, Rio de Janeiro, 1998.
. O Rio Grande do Sul na contracorrente da história. Vidya. Santa Maria, n. 24, p. 137-151, jul./dez. 1995.

HOLANDA, Sérgio Buarque. A herança colonial - sua desagregação. In: (Org.). História Geral da Civilização Brasileira. 6. ed. São Paulo: Difel, 1985. (Tomo II, v. 1). p. 9-39.

KLIEMANN, Luíza H. Schmitz. RS: Terra $\mathcal{E}$ Poder. História da Questão Agrária. Porto Alegre: Mercado Aberto, 1986.

LAZZARI, Alexandre. Entre a grande e a pequena pátria: letrados, identidade gaúcha e nacionalidade (1860-1910). 2004. Tese (Doutorado em História) - IFCH, Unicamp, Campinas, 2004.

MARTINS, Maria Fernanda Vieira. A velha arte de governar: um estudo sobre política e elites a partir do Conselho de Estado (1842-1889). 2005. Tese (Doutorado em História) - IFCS/ UFRJ, Rio de Janeiro, 2005.

MATTOS, Ilmar R. de. O Tempo Saquarema: a Formação do Estado Imperial. São Paulo: Hucitec, 1990.

MENEGAT, Carla. O tramado, a pena e as tropas. Família, Política e negócios do casal Domingos José de Almeida e Bernardina Rodrigues Barcellos. (Rio Grande de São Pedro, Século XIX). Dissertação (Mestrado em História) - PPGH/ UFRGS, Porto Alegre, 2009.

OSÓRIO, Helen. Apropriação da Terra no Rio Grande de São Pedro e a formação do espaço platino. Dissertação (Mestrado em História) - UFRGS-PPGH, Porto Alegre, 1990.

PESAVENTO, Sandra. República Velha Gaúcha: frigoríficos, charqueadas, criadores. Porto Alegre: Movimento/IEL, 1980.

PICCOLO, Helga Iracema Landgraf. Vida política no século 19. 3. ed. Porto Alegre: Editora da UFRGS, 1998. 
- A Politica Rio-Grandense no II Império (1868-1882). Porto Alegre: UFRGS, 1974.

RECKZIEGEL, Ana Luiza Setti. A diplomacia marginal: vinculações políticas entre o Rio Grande do Sul e o Uruguai (1893-1904). Passo Fundo: UPF Editora, 1999.

RIBEIRO, José Iran. De tão longe para sustentar a honra nacional: Estado e Nação nas trajetórias dos brasileiros na Guerra dos Farrapos. 2009. Tese (Doutorado em História) - PPGH/UFRJ, Rio de Janeiro, 2009.

SOUZA, Adriana Barreto. Duque de Caxias: o homem por trás do monumento. Rio de Janeiro: Civilização Brasileira, 2008.

SOUZA, Susana B.; PRADO, Fabrício. Brasileiros na fronteira uruguaia: economia e política no século XIX. In: GRIJÓ, Luiz A. et al. Capítulos de história do Rio Grande do Sul. Porto Alegre: EDUFRGS, 2004.

THOMPSON FLORES, Mariana Flores da Cunha; FARINATTI, Luis Augusto Eibling. A fronteira manejada: apontamentos para uma história social da fronteira meridional do Brasil (século XIX). In: HEINZ, Flávio Madureira (Org.). Experiências Nacionais, temas transversais: subsídios para uma história comparada da América Latina. São Leopoldo: Oikos, 2009. p. 145-177.

THOMPSON FLORES, Mariana Flores da Cunha. Contrabando e contrabandistas na fronteira Oeste do Rio Grande do Sul (1851-1864). Dissertação (Mestrado em História) - UFRGS/ PPGH, Porto Alegre, 2007.

TRINDADE, Helgio; NOLL, Maria Izabel. Rio Grande da América do Sul: partidos e eleições (1823-1990). Porto Alegre: EDUFRGS/Sulina, 1991.

URICOECHEA, Fernando. O minotauro imperial: a burocratização do estado patrimonial brasileiro no século XIX. São Paulo: Difel, 1978.

VARGAS, Jonas Moreira. Entre a paróquia e a Corte: uma análise da elite política do Rio
Grande do Sul (1868-1889). 2007. Dissertação (Mestrado em História) - PPG em História/ UFRGS, Porto Alegre, 2007.

ZABIELA, Eliane. A presença brasileira no Uruguai e os Tratados de 1851 de Comércio e Navegação, de Extradição e de Limites. 2002. Dissertação (Mestrado em História) - PPGH/UFRGS, Porto Alegre, 2002. 